\title{
A Framework for Utilizing Fire Property Tests
}

\author{
THOMAS G. CLEARY
}

Building and Fire Research Laboratory

National Institute of Standards and Technology

Gaithersburg, Maryland 20899. USA

\section{JAMES G. QUINTIERE}

Department of Fire Protection Engineering

University of Maryland

College Park, Maryland 20742, USA

\section{ABSTRACT}

A complete approximate set of equations is developed to describe fire spread over a surface and its resultant energy release. Wall, floor, and ceiling orientations are considered. The needed model data are couched in terms of available test method results, e.g., Cone calorimeter and LIFT apparatuses. Several applications are presented to show how energy release rates can be predicted and how well they represent real data from fullscale and model room lining experiments.

KEYWORDS: Energy release, fire property tests, linings, predictions, room fires.

\section{INTRODUCTION}

Theories of flame spread and new widely used test apparatuses capable of providing engineering fire property data make it feasible to construct a framework for fire hazard assessment. The test apparatuses include the Cone Calorimeter [1], and the Lateral Ignition and Flame Spread Test (LIFT) [2], both of which have been recently established as ASTM standard methods and are being considered in ISO. We shall formulate a model to compute the energy release rate of the fire as a function of time in terms of the material orientation and properties.

The model to be presented, we emphasize, represents only a framework for a more complete and precise solution to the appropriate characterization of materials through fire test methods. Our results and our model

This paper is a contribution of the National Institute of Standards and Technology and is not subject to copyright. 
should serve as support for other analyses which have used similar property data to predict the flashover times for actual experiments [3-5]. However, we believe that our model is less empirical and more physically complete than these previous analyses $[3-5]$.

\section{THEORETICAL DEVEIDPMENT}

The essential elements of fire growth have been included; namely, ignition, energy release rate, burning time, and all relevant modes of flame spread for the surface orientation considered. Also, the effects of the ignitor and thermal feedback have been parametrically considered. Detailed transient characteristics and room smoke layering have been ignored, but their contributions eventually need to be assessed.

\section{Fire Properties}

The term "fire properties" will be used to describe the input material data for the model. Our "fire properties" will not necessarily be unique, but will depend on environmental conditions. These are described below:

1. $\dot{Q}^{\prime \prime}$, average peak heat release rate per unit area. This value is derived from the Cone Calorimeter [1] for which the transient data have been averaged, and evaluated

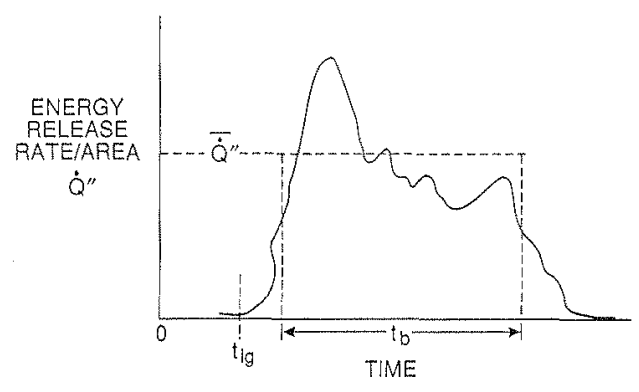

Figure 1 Energy release property data at a specified irradiance level.

It is illustrated in Figure 1 in which the area under the actual curve is approximately equal to the area under the rectangle. We have not used a standardized prescription for determining the average energy release rate and burn time. This was done in a consistent manner by approximating the significant burning region of the curve by a square wave. We selected an average maximum for $\tilde{Q}^{\prime \prime}$ and then estimated $t_{b}$ to maintain the total energy.

2. $t_{b}$, burn time. This value is the width of the approximating rectangle in Figure 1. This also corresponds to a given heat flux, and is derivable fxom the Cone Calorimeter.

3. $t_{i g}$, ignition time. This value is the time for piloted ignition at a given heat flux, specifically radiative. The heat flux level should be selected to correspond to the flame heat flux level appropriate to windaided flame spread.

4. $\Phi$, flame heating parameter in opposed flow spread. This "property" is directly derivable from the LIFT $[2,6]$ standard procedure. It represents the flame heat transfer and opposed flow velocity effects.

5. $T_{s, m i n}$, minimum temperature for flame spread. In opposed flow flame spread it is found that materials require a minimum heating level to achieve a surface temperature required for spread. Below this temperature spread is not possible. This temperature is also required but not available for, wind-aided or upward flame spread. For example, it appears 
that a preheated surface temperature in excess of $80^{\circ} \mathrm{C}$ is necessary to cause sustained upward flame spread on wood particle board [7].

\section{Equations}

In developing the governing equations we shall consider all materials to be thermally thick, i.e. no effect of thickness, and laminated materials and substrates are treated as homogeneous, reflective of their bulk properties. The same corresponding equations will apply, without distinction, to horizontal (floor), lateral, and downward wall spread as opposed flow spread; and to upward wall and ceiling spread as wind-aided spread. One might argue with this lack of distinction but the opposed flow case for these different orientations has some support [8] whereas the extension of the upward spread theory to the ceiling is only a convenience for now which needs further study. For all orientations, as illustrated in Figure 2, symmetry is invoked, and the wind-aided coordinate is designated by $y$ and the opposed flow coordinate by $x$. Spread on the floor (Fig, 2a), and ceiling (Fig. 2b) is radially symmetric, and on the wall (Fig. 2c) is approximated and as a region developed from two ( $x$ and $y$ ) spreads away from an initi-

(a)

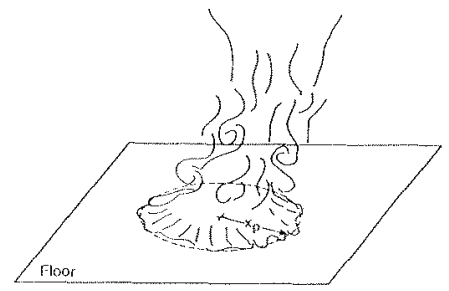

(b)

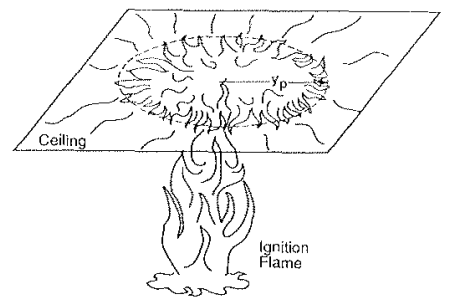

(c)

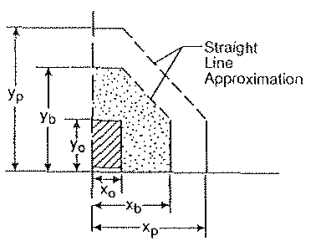

Figure 2 Model floor, ceiling, wall configurations ally ignited rectilinear zone of area $2 \mathrm{x}_{0} \mathrm{y}_{0}$. The region between the extended pyrolysis wall fronts $\left(x_{p}, y_{p}\right)$, and the burnout fronts $\left(x_{b}, y_{b}\right)$ is formed by straight line approximations (Fig. 2c).

The objective of our analysis is to compute the energy release rate, $\dot{Q}(t)$, as a function of time for the orientation shown in Figure 2 or their combination. For energy release we write the following approximation based on Figure 1 .

$\dot{Q}(t)=\iint \dot{Q} " d x d y=\dot{Q}^{\prime \prime} A_{p}$

where $A_{p}$ is the pyrolysis or volatilizing area.

For the floor or ceiling cases it can easily be shown that

$A_{p}=\pi\left(x_{p}^{2}-x_{b}^{2}\right)$ or $\pi\left(y_{p}^{2}-y_{b}^{2}\right)$

For the wall case,

$A_{p}=2\left[y_{p} x_{0}+\left(x_{p}-x_{0}\right) y_{0}+1 / 2\left(y_{p}-y_{0}\right)\left(x_{p}-x_{0}\right)\right]$ for $t \leq t_{b}$

or 
$\begin{aligned} A_{p}= & 2\left[y_{p} x_{0}+x_{p} y_{0}+1 / 2\left(y_{p}-y_{0}\right)\left(x_{p}-x_{0}\right)\right] \quad \text { for } t>t_{b} \\ & -2\left[y_{b} x_{0}+x_{b} y_{0}+1 / 2\left(y_{b}-y_{0}\right)\left(x_{b}-x_{0}\right)\right]\end{aligned} \quad$

In order to formulate the rest of the analysis we write out and solve the equations for the pyrolysis and burnout fronts.

Wind-aided Solution

The upward ox wind-aided solution is developed [9] from the equation

$\frac{d y_{p}}{d t}=\frac{y_{f}-y_{p}}{t_{i g}}$

where $y_{f}$ is the position of the flame tip with $y_{f}-y_{p}$ defining the forward heat transfer region of the flame identified with heat flux, $\dot{q}_{f}^{\prime \prime}$ Equation (4) is a quasi-steady model which uses the steady-state flame spread result successively over time as the forward heat transfer region changes. Mathematically, this solution is continuous. This flame heat flux will be taken as $30 \mathrm{~kW} / \mathrm{m}^{2}$ in our analysis for all materials.

The ignition time is given as

$t_{i g}=\frac{\pi k \rho c\left(T_{i g}-T_{s}\right)^{2}}{4\left(\dot{q}_{f}^{n}\right)^{2}}$

where $T_{i g}$ is the ignition temperature, kpc is the thermal inertia, and $T_{s}$ is the surface temperature of the region $y \geq y_{f}$. As can be seen, the "property" $t_{i g}$ can be related to more valid engineering materials properties (kpc and $\mathrm{T}_{\mathrm{ig}}$ ) and other factors.

Finally, the flame length can be estimated by a linear approximation to wall fire data [9] as

$\mathrm{y}_{f}-\mathrm{y}_{\mathrm{b}}=\mathrm{k}_{\mathrm{f}}\left[\dot{\mathrm{Q}}_{0}^{\prime}+\overline{\mathrm{Q}}^{\prime \prime}\left(\mathrm{y}_{\mathrm{p}}-\mathrm{y}_{\mathrm{b}}\right)\right]$

where $y_{b}$ is taken as identically zero for $t \leq t_{b}$, and $\dot{Q}_{0}$ is the energy release rate per unit width of the ignitor flame needed co start the process. This ignitor flame is assumed to provide a uniform heat flux $\left(\dot{q}_{f}^{\prime \prime}\right)$ of $30 \mathrm{~kW} / \mathrm{m}^{2}$ over the region $\left(\mathrm{x}_{0}, \mathrm{y}_{0}\right)$ which is taken to ignite at $t=t_{i g}$ in Eqn. (5), or corresponding to $t_{1 g}$ in Fig. 1. The value for $k_{f}$ is approximately $0.01 \mathrm{~m}^{2} / \mathrm{kW}$. In Eqn. (6), the term $\dot{Q}_{0}^{\prime}$ is set to zero when $t>t_{b}$. This is done after $t=t_{b}$ since the initial region as determined by the flame extent due to $\dot{Q}_{0}^{\prime}$ is no longer burning, and subsequently the ignitor flame would become discontinuous from the material flame ahead of this region. This ignitor energy is continuously included in the overall heat release.

The burnout front can be approximated as

$\frac{d y_{b}}{d t}=\frac{y_{p}-y_{b}}{t_{b}} \quad$ for $t>t_{b}$

The initial conditions are given as:

$t=0, y_{p}=y_{0}$

$t=t_{b}, y_{p}=y_{p}\left(t_{b}\right), y_{b}=y_{0}$. 
The solutions to the above are given below:

$\eta=\left(\frac{a+1}{a}\right) e^{a \tau}-1 / a$

for $0 \leq \tau \leq t_{b} / t_{i g}$ where $\tau=t / t_{i g}, \quad \eta=y_{p} / y_{0}, \quad a=k_{f} \dot{Q}^{\prime \prime}-1$, and $\mathrm{y}_{0}=\mathrm{k}_{f} \dot{\mathrm{Q}}_{0}^{\prime}$. This assumes that the initial pyrolysis length, $y_{0}$, is determined by the height of the ignition flame. For $\tau>\left(t_{b} / t_{i g}\right) \equiv \tau_{b}$. Eqns. (4) and (7) are subtracted and solved to yield

$\psi \equiv \frac{\mathrm{y}_{\mathrm{p}}-\mathrm{y}_{\mathrm{b}}}{\mathrm{y}_{\mathrm{o}}}=\mathrm{c} \mathrm{e}^{\mathrm{b}\left(\tau-r_{\mathrm{b}}\right)}$

where $b=a-1 / \tau_{b}$ and $c=\left(\frac{a+1}{a}\right)\left[e^{a r_{b}}-1\right]$. From Eqn. (7) it follows that $\eta_{\mathrm{b}}=\mathrm{y}_{\mathrm{b}} / \mathrm{y}_{\mathrm{o}}$ is given by

$\eta_{\mathrm{b}}=1+\frac{\mathrm{c}}{\mathrm{b} r_{\mathrm{b}}}\left(\mathrm{e}^{\mathrm{b}\left(\tau-r_{\mathrm{b}}\right)}-1\right)$

The parameters $a$ and $b$ must be greater than zero in order for the upward fire spread to accelerate. For values less than zero, the spread will eventually stop. This bimodal behavior is a distinct characteristic of upward flame spread which is conditional on the form of Eqn. (6). This clearly shows the role of the energy release rate per unit area and its duration in time, i.e., $\dot{Q}^{\prime \prime}$ and $t_{\mathrm{b}}$.

Opposed flow solution

From the LIFT procedure $[2,6]$ the governing equation for the pyrolysis position is

$\frac{\mathrm{dx}_{\mathrm{p}}}{\mathrm{dt}}=\frac{\Phi}{\mathrm{k} \rho \mathrm{c}\left(\mathrm{T}_{\mathrm{ig}}-\mathrm{T}_{\mathrm{s}}\right)^{2}} \quad$ for $\mathrm{T}_{\mathrm{s}} \geq \mathrm{T}_{\mathrm{s}, \min }$.

This can be rewritten as

$\frac{d x_{p}}{d t}=\frac{\frac{\pi}{4\left(\dot{q}_{\tilde{r}}^{*}\right)^{2}}}{t_{i g}}$

The dimensionless solution $\xi \equiv x_{p} / x_{0}$ follows as

$\xi=\beta r+1 \quad$ where $\beta=\frac{\pi \Phi x_{0}}{4\left(\dot{q}_{\varepsilon}\right)^{2}}$

The burnout solution analogously follows from Eqn. (7), i.e.

$\frac{d x_{b}}{d t}=\frac{x_{p}-x_{b}}{t_{b}}$

and it can be shown that $\xi_{\mathrm{b}}=x_{\mathrm{b}} / \mathrm{x}_{0}$ is given by

$$
\xi_{\mathrm{b}}=\beta\left(\tau-\tau_{\mathrm{b}}\right)+1, \tau \geq \tau_{\mathrm{b}}
$$


This completes the solution. These equations will now be applied to specific applications. For each case we shall appropriately apply the equations by accounting for the effects of geometry and thermal feedback as a parameter. For example, a corner wall and ceiling fire will be considered as an extended vertical wall representative of the actual corner wall and ceiling fet region plus a quadrant of a circular ceiling. To review, the procedure for implementing this solution is as follows:

1. Assemble material data namely, $\dot{\mathrm{Q}}^{\prime \prime}, \mathrm{t}_{1 \mathrm{~g}}, \mathrm{t}_{\mathrm{b}}, \Phi$ and $\mathrm{T}_{\mathrm{s}, \mathrm{min}}$.

2. Prescribe the ignition source, $\dot{Q}_{0}^{\prime}$ '

3. Since no room fire model is coupled to this analysis, one must set $T_{s}$ at a value representative of the particular room configuration.

4. Compute the pyrolysis area $A_{p}$ for the surface configuration using the formulas for $x_{p}$ and $y_{p}$.

5. Compute the fire product output rate, e.g. rate of any energy release, by multiplying $A_{p}$ by $\tilde{Q}^{\prime \prime}$.

\section{APPLICATIONS}

Several applications of the analysis will be presented for cases where scenario results for total energy release exist along with a complete set of fire property data.

\section{Fu11. Scale Room - Corner Tests}

A series of full scale room lining fire tests were performed at the Swedish National Testing Institute, Borás, Sweden [10]. The test scenario consisted of lining the walls and ceiling of the room $(2.43 \mathrm{~m}$ by $3.66 \mathrm{~m}$ by $2.43 \mathrm{~m}$ in height with an opening $2 \mathrm{~m}$ by $0.9 \mathrm{~m}$ ) with a given material. A $0.17 \mathrm{~m}$ by $0.17 \mathrm{~m}$ propane sand burner was placed in the corner of the room. Initially a $100 \mathrm{~kW}$ fire was allowed to burn in the corner. If this fire did not cause flashover in 10 minutes, then the burner output was increased to $300 \mathrm{~kW}$.

Small scale fire test data were obtained by other researchers for the materials used in the Boràs study $[5,11,12]$ and were used to develop Table 1 . These values are used for the model inputs. In the calculations, ceiling fire spread is accounted for by having the ceiling ignite when the pyrolysis front reaches the ceiling. The celling spread follows the wind-aided spread along the wall ceiling interface. Thus, the pyrolyzing ceiling area is given as the quadrant of the ceiling with a radius equal to the distance from the corner to the wall ceiling interface pyrolyzing front. Lateral spread was

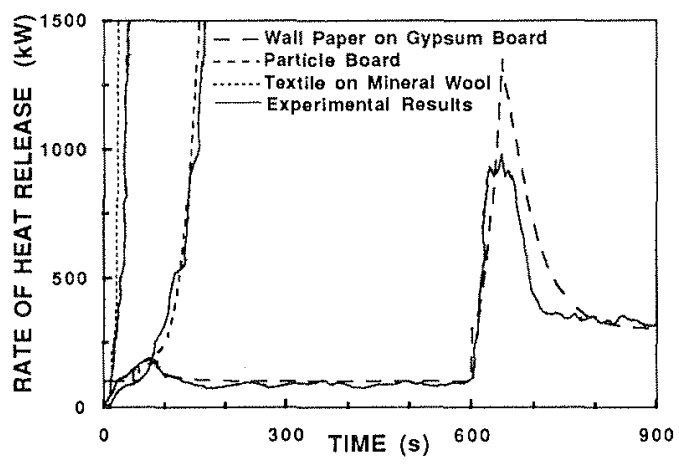

Figure 3 Energy release predictions for the Swedish data $\left(\mathrm{T}_{\mathrm{s}}=80^{\circ} \mathrm{C}\right.$, irradiance level $=25 \mathrm{~kW} / \mathrm{m}^{2}$ ). 
allowed to occur only if the wall surface temperature is at the material's $\mathrm{T}_{\mathrm{s}, \mathrm{min}}$ or greater. The model was rum with $\mathrm{T}_{\mathrm{s}}$ at $25^{\circ} \mathrm{C}$ and $80^{\circ} \mathrm{C}$. While at the start of the test the surface temperature is uniform (about $25^{\circ} \mathrm{C}$ ), allowing $\mathrm{T}_{\mathrm{s}}$ to be an input parameter shows the sensitivity to feedback and the effects which increased lateral spread has on the results. This is justified because, while early on in the test $T_{s}$ of $25^{\circ} \mathrm{C}$ is more representative of the room conditions, the upper layer temperature is always increas. ing and radiative feedback is raising wall and ceiling temperatures. We selected burner flame heights $\left(y_{0}\right)$ of $1.3 \mathrm{~m}$ and $2.1 \mathrm{~m}$ for the 100 and $300 \mathrm{~kW}$ settings. We determined $y_{0}$ values from an axisymmetric fire plume correlation realizing that corner flames would be taller and could interact with the ceiling. For cases that stopped propagating before 10 minutes, the analysis was restarted at $t=600 \mathrm{~s}$ from a new origin at $y_{b}(600 \mathrm{~s})$. If $y_{b}(600 \mathrm{~s})$ is greater than $2.1 \mathrm{~m}$, the ignitor flame height, we arbitrarily selected $0.3 \mathrm{~m}$ as a new $y_{0}$ in order to initiate spread again. Also for $t>600 \mathrm{~s}$, we selected $\mathrm{T}_{\mathrm{s}}=250^{\circ} \mathrm{C}$ based on the maximum gas temperatures measured [10]. Model predictions and experimental results for the time to a $1 \mathrm{MW}$ fire are given in Table 2. Figures 3 and 4 show the experimental rate of heat release as a function of time (solid curves) and model calculations (dashed curves) with $\mathrm{T}_{\mathrm{s}}=80^{\circ} \mathrm{C}$ for six of the materials. The results are comparable to the calculations of Karlsson [5], but appear to be distinctly better than the results of Wickstrom and Goransson [3].

Table 1 Fire Properties of Swedish Fire Test Materials

Material

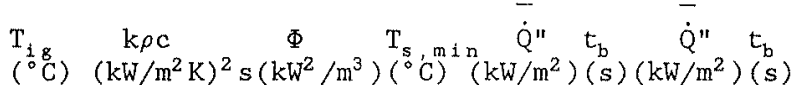

$$
\begin{aligned}
& \left(25 \mathrm{~kW} / \mathrm{m}^{2}\right)\left(50 \mathrm{~kW} / \mathrm{m}^{2}\right)
\end{aligned}
$$

\begin{tabular}{|c|c|c|c|c|c|c|c|c|}
\hline Particle Board & 405 & 0.626 & 8 & 180 & 140 & $>500$ & 200 & $>500$ \\
\hline Insulating Fiberboard & 381 & 0.229 & 14 & 90 & 120 & $>500$ & 150 & $>300$ \\
\hline Medium Density Fiberboard & 361 & 0.732 & 11 & 80 & 140 & $>500$ & 170 & $>600$ \\
\hline Wood Panel (Spruce) & 389 & 0.569 & 24 & 155 & 140 & $>200$ & 160 & $>400$ \\
\hline Melamine on Particle Board & 483 & 0.804 & $<1$ & 435 & - & - & 115 & $>400$ \\
\hline Wall Paper on Gypsum Board & 388 & 0.593 & 0.5 & 300 & 100 & 40 & 200 & 20 \\
\hline PVC on Gypsum Board & 410 & 0.208 & 25 & 300 & 105 & 20 & 160 & 20 \\
\hline Textile on Gypsum Board & 406 & 0.570 & 9 & 270 & 200 & 30 & 300 & 20 \\
\hline Textile on Mineral Wool & 391 & 0.183 & 6 & 174 & 250 & 30 & 375 & 20 \\
\hline Paper on Particle Board & 426 & 0.680 & 13 & 250 & 140 & $>500$ & 150 & $>500$ \\
\hline Rigid Polyurethane Foam & 393 & 0.031 & 3 & 105 & 110 & 60 & 180 & 60 \\
\hline Expanded Polystyrene Foam & 482 & 0.464 & - & - & - & - & 300 & 100 \\
\hline Gypsum Board & 469 & 0.515 & 14 & 380 & - & - & 100 & 20 \\
\hline
\end{tabular}

Data were not taken

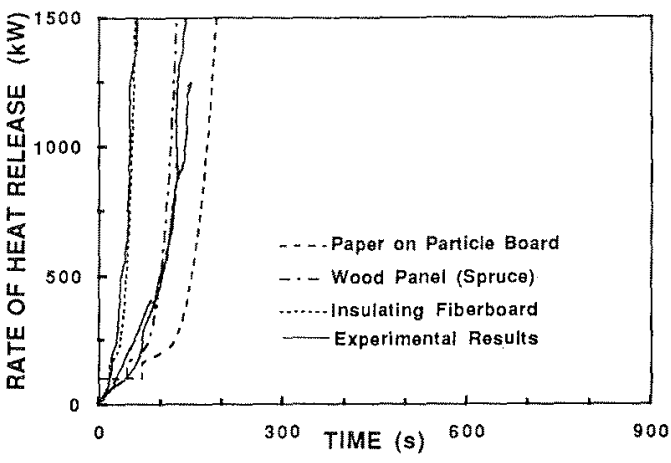

Figure 4 Energy release predictions for the Swedish data $\left(\mathrm{T}_{\mathrm{s}}=80^{\circ} \mathrm{C}\right.$,
irradiance level $\left.-25 \mathrm{~kW} / \mathrm{m}^{2}\right)$.

(1)


Table 2 Tine to Achieve a 1 MW Fire for the Swedish Room Tests

Experimental. Time

Particle Board

Insulating Fiberboard

Medium Density Fiberboard

Wood Pane1 (Spruce)

Melamine on Particle Board

Wall Paper on Gypsum Board

PVC on Gypsum Board

Textile on Gypsum Board

Textile on Mineral Wool

Paper on Particle Board

Rigid Polyurethane Foam

Expanded Polystyrene Foam

Gypsum Board

157

59

131

131

465

640

611

639

43

143

6

115

*
Model Calculations

$\left(25 \mathrm{~kW} / \mathrm{m}^{2}\right) \quad\left(50 \mathrm{~kW} / \mathrm{m}^{2}\right) \quad\left(25 \mathrm{~kW} / \mathrm{m}^{2}\right)$

$\left(\mathrm{T}_{\mathrm{s}}=25^{\circ} \mathrm{C}\right)\left(\mathrm{T}_{\mathrm{s}}=25^{\circ} \mathrm{C}\right)\left(\mathrm{T}_{\mathrm{s}}=80^{\circ} \mathrm{C}\right)$

(s)

(s)

(s)

198
77
180
165
-
632
619
615
33
237
11
-
-

143

143
58

$58 \quad 55$

$148 \quad 125$

143

402

616

606

613

28

220

6

122

117

641

622

615

24

177

7

$*$

- Data were not taken

* Did not reach $1 \mathrm{MW}$

Textile Wall Covering Room Tests

A series of textile wall fire tests was performed by the U.C., Berkeley for the American Textile Manufactures Institute [13]. In these

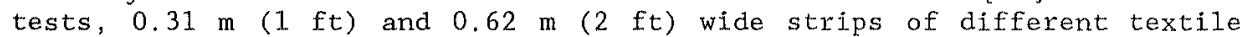
wall covering materials were applied to a corner section and the wall portion of the wall-ceiling interface of a room with roughly the same dimensions of the room described above. A $0.31 \mathrm{~m}$ by $0.31 \mathrm{~m}$ propane sand burner was placed in the material lined cornex approximately $10 \mathrm{~cm}$ from the walls. A small $40 \mathrm{~kW}$ fire was allowed to burn in the corner for 5 minutes, then the burner output was increased to $150 \mathrm{~kW}$. The position of the burner and the size of the small $40 \mathrm{~kW}$ fire was such that in most cases it did not cause the textile material to ignite, but shortly after the burner output was increased to $150 \mathrm{~kW}$, all wall lining materials ignited. The rate of heat release was obtained during each test. The data for input into the model is given by Harkleroad [14]. Here lateral spread was not included in the calculations since lateral spread is not expected with the $0.31 \mathrm{~m}$ wide strips anyway. It appears from the experimental results that the $40 \mathrm{kw}$ fire only served to preheat the room, therefore we picked an initial surface temperature of $100^{\circ} \mathrm{C}$ based on the maximum gas temperatures measured during this preheating time. Table 3 shows the experimental and calculated results. By examining the $0.31 \mathrm{~m}$ and $0.62 \mathrm{~m}$ wide strip results, it appears in some cases lateral spread is significant. The model calculations were performed for the $0.31 \mathrm{~m}$ wide strip cases using Cone Calorimeter data at external irradiances of 30 and $50 \mathrm{~kW} / \mathrm{m}^{2}$. Ignition delay times for each of the materials were calculated from Eq. (5). For this calculation, we assumed $\mathrm{T}_{\mathrm{s}}=100^{\circ} \mathrm{C}$ and $60 \mathrm{~kW} / \mathrm{m}^{2}$ to represent the heat flux of the ignitor [15], and added the calculated ignition time to the model calculated time to reach the peak rate of heat release. The peak rate of heat release and the time interval from the start of the $150 \mathrm{~kW}$ fire for the $0.31 \mathrm{~m}$ strips are in fair agreement with the calculations. After the peak heat release 
was obtained a rapid decay was observed experimentally for most cases, this was predicted well by the model.

Table 3 Textile Wall Coverings Room Fire Tests

Full Scale Screening Tests $(0.31 \mathrm{~m}$ width $)(0.62 \mathrm{~m}$ width $)$ $\begin{array}{cccc}\dot{\mathrm{Q}}_{\mathrm{p}} & \mathrm{t}_{\mathrm{p}}^{*} & \dot{\mathrm{Q}}_{\mathrm{p}} & \mathrm{t}_{\mathrm{p}}^{*} \\ (\mathrm{~kW}) & (\mathrm{s}) & (\mathrm{kW}) & (\mathrm{s})\end{array}$
Model Calculations

$\begin{array}{cccc}\dot{Q}_{p} & t_{p}^{*} & \dot{Q}_{p} & t_{p}^{*} \\ (k W) & (s) & (k W) & (s)\end{array}$ $\left(30 \mathrm{~kW} / \mathrm{m}^{2}\right) \quad\left(50 \mathrm{~kW} / \mathrm{m}^{2}\right)$

Material

\begin{tabular}{|c|c|c|c|c|c|c|c|c|}
\hline (H) $85 \%$ wool $15 \%$ cotton & 46 & 30 & 160 & 40 & \multicolumn{2}{|c|}{ - } & 146 & $\overline{46}$ \\
\hline (C) 558 cotton 458 rayon & 62 & 30 & 119 & 60 & 137 & 40 & 139 & 37 \\
\hline (G) 1008 polyester & 83 & 30 & & & 64 & 39 & 56 & 44 \\
\hline (B) $100 \%$ polyester & 207 & 45 & 298 & 60 & 121 & 46 & 270 & 46 \\
\hline (Q) 100 polyester & 207 & 40 & 480 & 40 & 145 & 50 & 293 & 55 \\
\hline (Qfr) 1008 polyester & 310 & 40 & & & 157 & 43 & 292 & 59 \\
\hline (R) 1008 nylon & 587 & 70 & 590 & 70 & 46 & 46 & 416 & 51 \\
\hline (AA) 708 acrylic 308 wool & 684 & 30 & & & 725 & 109 & 744 & 106 \\
\hline (PPPF) polypropylene & & & 337 & 50 & 271 & 45 & 450 & 48 \\
\hline
\end{tabular}

$\dot{Q}_{\mathrm{p}}=$ peak energy release rate

$t_{p}^{*}=$ time interval from start of $150 \mathrm{~kW}$ burnex to peak energy release rate

\section{CONCLUDING REMARKS}

We have presented evidence that an engineering approach utilizing "fixe property" data from test methods can satisfactorily predict full scale energy release of room lining fires. The choice of the fire properties used is somewhat arbitrary until the fire heat transfer conditions can be related to the test method irradiance levels. The framework presented should serve as a basis for further analysis, but it could be used now to estimate the fire growth hazard of lining materials.

\section{Acknowledgement}

We are grateful to $\mathrm{Mr}$. Richard Gottwald and the Society of Plastics Industries for partial support in developing this study.

Nomenclature

$\begin{array}{ll}\text { A } & \text { area } \\ \text { a dimensionless parameter, Eq. (9) } \\ \mathrm{b} & \text { dimensionless parameter, Eq. (10) } \\ \mathrm{c} & \text { dimensionless parameter, Eq. (10) } \\ \mathrm{k} \rho \mathrm{c} & \text { thermal inertia } \\ \mathrm{k}_{\mathrm{f}} & \text { constant, } 0.01 \mathrm{~m}^{2} / \mathrm{kW}, \mathrm{Eq} .(6) \\ \mathrm{q} & \text { heat transfer } \\ \mathrm{Q} & \text { energy } \\ \mathrm{t} & \text { time } \\ \mathrm{T} & \text { temperature } \\ \mathrm{x} & \text { opposed flow coordinate direction }\end{array}$

Subscripts:

b burnout

f flame

ig ignition

o initial

p pyrolysis 
y wind-aided coordinate direction

$\beta$ dimensionless parameter, Eq. (14)

$r$ dimensionless time, $t / t_{b}$

$\xi$ dimensionless pyrolysis position, $x_{p} / x_{0}$

$\xi_{\mathrm{b}}$ dimensionless burnout position, $\mathrm{x}_{\mathrm{b}} / \mathrm{x}_{\mathrm{o}}$

$\eta$ dimensionless pyrolysis position, $y_{p} / y_{0}$

$\eta_{\mathrm{b}}$ dimensionless burnout position, $\mathrm{y}_{\mathrm{b}} / \mathrm{y}_{\mathrm{o}}$

$\Phi$ flame heating parameter, Eq. (12)
Superscripts:

\section{(') average}

(·) per unit time

( )" per unit area

(). per unit width

\section{REFERENCES}

1. Standard Test Method for Heat and Visible Smoke Release Rates for Materials and Products Using an Oxygen Consuption Calorimeter, (ASTM E 1354), Amer. Soc. for Testing and Materials, Philadelphia.

2. Quintiere, J.G. and Harkleroad, M., "New Concepts for Measuring Flame Spread Properties", pp. 239-267 in Fire Safety Science and Engineering (ASTM STP 882), Amer.Soc. for Testing and Materials, Philadelphia, PA, 1985.

3. Wickström, U., Göransson, U., "Prediction of Heat Release Rates of Surface Materials in Large-Scale Fire Tests Based on Cone Calorimeter Results", ASTM Journal of Testing and Evaluation, Vo1. 15, No. 6, 1987.

4. Östman, B., and Nussbaum, R., "Correlation Between Small-Scale Rate of Heat Release and Full-Scale Room Flashover for Surface Linings", pp. 823-832 in Fire Safety Science Proc. of the Second International Symposium (1988), Hemisphere Publishing, New York (1989).

5. Karlsson, B., "Room Fires and Combustible Linings", Dept. of Fire Safety Engineering, Lund Institute of Science and Technology, Report, Lund, 1989.

6. Standard Method for Determining Material Ignition and Flame Spread Properties, (ASTM E 1321), Amer. Soc. for Testing and Materials, Philadelphia.

7. Saito, F., Williams, F.A., Wichman, I.S. and Quintiere, J.G., "Upward Turbulent Flame Spread on Wood Under External Radiation", Journal of Heat Transfer, pp. 438-445, Vol. 111, May 1989.

8. Quintiere, J.G., "The Application of Flame Spread Theory to Predict Material Performance", Journal of Research of the Nat. Bur. of Stds., pp. 61-70, Vol. 93, No. 1, Jan,-Feb. 1988.

9. Quintiere, J.G., Harkleroad, M. and Hasemi, Y., Combustion Science Technology, Vo1. 48, 1986.

10. Sundström, B., "Full Scale Fire Testing of Surface Materials", Technical Report SP-RAPP 1986:45, Swedish National Testing Institute, Boràs 1986.

11. Quintiere, J., Harkleroad, M., "New Concepts for Measuring Flame Spread Properties", National Bureau of Standards (U.S.) NBSIR 84-2943, 1984.

12. Tsantaridis, L. and Östman, B., "Smoke, Gas and Heat Release Data for Building Products in the Cone Calorimeter", TrateknikCentrum, Report I $8903013,1989$.

13. Fisher, F., MacCracken, B., and Williamson, R., "Room Fire Experiments of Textile Wall Coverings", Fire Research Laboratory, University of California, Berkeley, California, 1986.

14. Harkleroad, M., "Fire Properties Database for Textile Wall Coverings", National Institute of Standards and Technology (U.S.), NISTIR 894065 , 1989 .

15. Mowrer, F., Private Communications, Univ. of Maryland, July 1990. 